\title{
НАУЧНЫИ ОБЗОР
}

УДК 575:613-98(063)

doi: 10.31140/j.vestnikib.2019.2(209).1

\section{АРОНИЯ ЧЕРНОПЛОДНАЯ (ARONIA MELANOCARPA) КАК ИСТОЧНИК СОЕДИНЕНИЙ С ПОТЕНЦИАЛЬНОЙ ГЕРОПРОТЕКТОРНОЙ АКТИВНОСТЬЮ}

\author{
Е.Ю. Платонова ${ }^{1}$ С.Н. Плюснин ${ }^{2}$, М.В. Шапошников ${ }^{1}$, А.А. Москалев ${ }^{1,2}$ \\ ${ }^{1}$ Институт биологии Коми научного центра Уральского отделения Российской академии наук, Сыктывкар \\ ${ }^{2}$ Сыктывкарский государственный университет им. Питирима Сорокина, Сыктывкар \\ E-mail: dega37@yandex.ru
}

\begin{abstract}
Аннотация. Арония черноплодная (Aronia melanocarpa (Micht.) Elliot) известна как ценная плодовая культура. В статье представлен обзор эффектов экстрактов стеблей, листьев и ягод $A$. melanocarpa на продолжительность жизни модельных организмов, а также потенциальных последствий применения экстрактов аронии для организма в целом. Анализ литературы показывает, что экстракт аронии черноплодной способствует увеличению продолжительности жизни и является потенциальным геропротектором.
\end{abstract}

Ключевые слова: арония черноплодная, экстракт, геропротектор, продолжительность жизни, полифенольные соединения, антоцианы

\section{Введение}

Новые научные тенденции предполагают использование натуральных продуктов (таких как экстракты растений или выделенные растительные соединения) как в терапии, так и в профилактике многочисленных заболеваний с целью поддержания здорового долголетия (Fontana, 2015). Многочисленные исследования подтвердили, что диета, богатая растительной пищей, дает определенные преимущества для здоровья человека и защищает от рака, сердечно-сосудистых заболеваний, диабета, остеопороза, нейродегенеративных заболеваний (Black chokeberry ..., 2014; Neuroprotective ..., 2017). По этой причине интерес к исследованию новых биологически активных молекул и их источников растет, особенно в пищевой промышленности, которая обратилась к внедрению различных натуральных компонентов в продукты питания для улучшения их функциональности.

Арония черноплодная (Aronia melanocarpa (Michx.) Elliot) известна как ценная плодовая культура. Она принадлежит к семейству розоцветные (Rosaceae), подсемейству яблоневые (Рomodieae) (Kokotkiewicz, 2010). Ее использовали в традиционной медицине. В последние годы аронию черноплодную начали применять в качестве пищевого красителя, кроме того, она является потенциальным источником ценных фитонутриентов.

Цель данного обзора состоит в обобщении имеющихся в литературе сведений о влиянии экстрактов аронии черноплодной на различные модельные объекты и внутриклеточные процессы для выявления ее потенциальных геропротекторных свойств.

Существуют основные критерии геропротектоpa (Developing ..., 2016):
1. Увеличение продолжительности жизни;

2. Улучшение биомаркеров старения;

3. Низкая токсичность;

4. Слабые побочные эффекты;

5. Улучшение качества жизни;

6. Эволюционный консерватизм мишени;

7. Воспроизводимость геропротекторных эффектов на различных модельных организмах;

8. Влияние одновременно на несколько ассоциированных со старением причин смерти млекопитающих и человека;

9. Увеличение стрессоустойчивости.

Ранее в исследованиях специалистов лаборатории геропротекторных и радиопротекторных технологий отдела радиоэкологии Института биологии Коми НЦ УрО РАН на моделях культур клеток человека, нематоды Caenorhabditis elegans и плодовой мушки Drosophila melanogaster было продемонстрировано, что такие компоненты диеты и биологически активные соединения растительного происхождения, как полисахариды (цитрусовые и яблочные пектины), каротиноиды (бета-каротин и фукоксантин), флавоноиды (кверцетин, (-)-эпикатехин, нарингин, лютеолин, хризин), фитоэкдистероиды серпухи венценосной Serratula coronata L. (20-гидроксиэкдизон и инокостерон), стероидные гликозиды пажитника сенного Trigonella foenum-graecum L. (диосцин и протодиосцин) и терпены пихты сибирской Abies sibirica обладают выраженными геропротекторными свойствами. Они увеличивают продолжительность жизни и замедляют процессы старения, а также повышают устойчивость животных к различным неблагоприятным факторам среды, таким как ионизирующее излучение, гипертермия, окислительный стресс и голодание (Влияние препаратов ..., 2014; The effect ..., 2014; Fucoxanthin ..., 2015; Effects ..., 2016; Geroprotective ..., 
ВЕСТНИК ИБ КОМИ НЦ УрО РАН 2019 № 2

2016; The evaluation ..., 2017). С использованием методов полногеномного секвенирования транскриптома и количественной ПЦР с обратной транскрипцией в реальном времени (ОТ-ПЦР) мы установили, что геропротекторые свойства веществ растительного происхождения могут быть обусловлены способностью модулировать уровень экспрессии генов стресс-ответа клетки (антиоксидантной защиты, белков теплового шока, репарации повреждений ДНК) и активность связанных со старением внутриклеточных сигнальных путей, включая MAPK, mTOR, Wnt, Notch и Нippo (Transcriptome ..., 2018).

\section{Содержание}

\section{биологически активных соединений}

Плоды аронии черноплодной содержат комплекс биологически активных веществ. Наиболее важными их составляющими являются полифенольные соединения, такие как проантоцианидины, антоцианы, флавоноиды и фенольные кислоты (Hudec, 2006; Borowska, 2016). Проантоцианидины (конденсированные таннины), отвечающие за вяжущий вкус аронии, представляют собой олигомерные и полимерные катехины, состоящие из (-)-эпикатехина. Проантоцианидины образуют комплексы с белками и полисахаридами. Антоцианины (цианидин-3-О-галактозид, цианидин-3-О-арабинозид, цианидин-3-О-ксилозид и цианидин-3-О-глюкозид) присутствуют во внешних частях кожуры плода и отвечают за цвет аронии черноплодной (Underutilized ..., 2013; Eremeeva, 2016). Флавоноиды аронии представлены также различными производными кверцетина: кверцетин-3-рутинозид, кверцетин-3-галактозид, кверцетин-3-глюкозид (Hudec, 2006; Borowska, 2016). Кроме того, плоды аронии содержат фенольные кислоты: неохлорогеновую, хлорогеновую и кофейную (Borowska, 2016). Содержание общих полифенолов и отдельных полифенольных соединений в аронии черноплодной представлено в табл. 1.

Дополнительно ягоды содержат минеральные вещества и микроэлементы: бор, фтор, железо, медь, цинк, марганец, молибден, кобальт и йод (Hudec, 2006). В них также представлены витамины и витаминоподобные соединения (табл. 2).

Имеющиеся экспериментальные данные свидетельствуют о том, что биологически активные соединения содержатся не только в плодах, но и в листьях аронии, при этом более молодые листья аронии содержат большее количество полифенолов (Thi, 2014). Показано, что экстракты листьев и ягод содержат больше биологически активных соединений по сравнению со стеблями (Comparative ..., 2018). На содержание биологически активных соединений аронии черноплодной влияют условия сушки. Лиофилизированные ягоды обладают наиболее выраженной антиоксидантной активностью. Сублимационная сушка

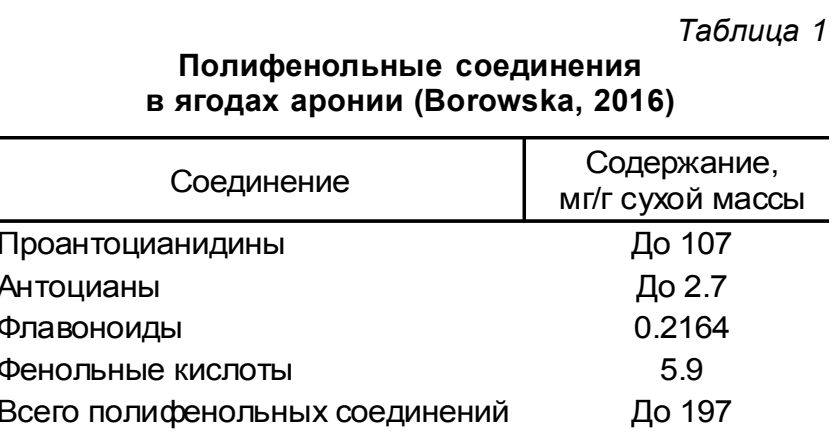

является оптимальной для поддержания высоких уровней биологически активных соединений в $80 \%$-ных этанольных экстрактах аронии черноплодной (Thi, 2016).

\section{Эксперименты по продлению жизни}

Исследований влияния вытяжек из A. melanocarpa на продолжительность жизни модельных организмов немного. В одной из недавних работ (Јо, 2017) показано, что применение экстракта A. melanocarpa в концентрации 2.5 мг/мл вызвало увеличение медианной (на $18 \%$ ) и максимальной (на $9 \%$ ) продолжительности жизни самцов плодовой мушки Drosophila melanogaster по сравнению с контрольной группой. Помимо этого, проводили анализ локомоторной активности D. melanogaster в тесте на отрицательный геотаксис. Было продемонстрировано, что двигательная активность значительно снижалась с возрастом и была существенно выше в группе с добавкой 2.5 мг/мл экстракта аронии как у молодых, так и старых особей в возрасте 10 и 40 сут. соответственно.

Данные результаты свидетельствуют о том, что экстракт аронии черноплодной не только увеличивает продолжительность жизни, но и способствует повышению двигательной активности в старости, а значит и улучшению качества жизни в целом. Увеличенная продолжительность жизни и улучшенная локомоция, вероятно, были обусловлены повышением уровней антиоксидантных ферментов (супероксиддисмутаза (SOD), каталаза (CAT) и глутатионпероксидаза (GPx) и активацией экспрессии генов, контролирующих стрессоустойчивость (Sod1, Sod2, Cat, Hsp68, l (2) efl и Jafrac1) (Јо, 2017).

Таблица 2

Витамины и витаминоподобные соединения в ягодах аронии черноплодной (Razungles, 1989)

\begin{tabular}{l|c}
\hline \multicolumn{1}{c|}{ Соединение } & $\begin{array}{c}\text { Содержание, } \\
\text { мкг/100 мл } \\
\text { сухой массы }\end{array}$ \\
\hline B1 (тиамин) & $25-90$ \\
B2 (рибофрлавин) & $25-100$ \\
В6 (пироксин) & $30-85$ \\
В9 (фолиевая кислота) & 4 \\
РP (ниацин) & $100-550$
\end{tabular}

Каротиноиды ( $\alpha$-каротин, $\beta$-каротин, ксантофилл, тараксантин) 


\section{Механизм воздействия на процессы старения}

Благодаря наличию и высокому содержанию полифенольных соединений, экстракты плодов A. melanocarpa обладают широким спектром положительных эффектов (табл. 3). Прежде всего, к благоприятным эффектам аронии относятся сильная антиоксидантная и противовоспалительная активность, а также гастропротекторное, гепатопротекторное и антипролиферативное действие (Kokotkiewicz, 2010; Fruits ..., 2017).

Оценку биологического потенциала экстрактов из листьев, стеблей и плодов аронии проводили путем определения их антиоксидантной активности (с использованием DPPH, ABTS и анализа перекисного окисления липидов), антимикробных свойств, способности ингибировать ферменты (холинэстераза и эластаза) и цитотоксического действия (на злокачественные клеточные линии HeLa, A-549, LS-174T и нормальные фибробласты легких MRC-5). Наиболее сильное ингибирование холинэстеразы и эластазы было обнаружено для экстракта из ягод. Точно так же экстракты, полученные из листьев и ягод, показали значительные цитотоксические эффекты на вышеупомянутые тестируемые клеточные линии (Comparative..., 2018). Помимо того было выявлено, что клетки HeLa гораздо более чувствительны к экстрактам аронии, чем A-549, LS-174T, MRC-5, тем самым демонстрируя противоопухолевые свойства экстрактов аронии (Comparative ..., 2018).

Экстракт аронии черноплодной (в концентрациях 1, 5 и 10 мкмоль/л в пересчете на антоцианы) вызвал увеличение уровня таких антиоксидантных ферментов, как супероксиддисмутаза
(SOD), каталаза (CAT) и глутатионпероксидаза $(\mathrm{GPx})$ в $\beta$-клетках поджелудочной железы по сравнению с клетками, подвергшимися воздействию прооксидантнов (перекисью водорода $\left(\mathrm{H}_{2} \mathrm{O}_{2}\right)$ и высокой концентрации глюкозы) (Rugina, 2015).

Применение экстрактов аронии оказывает влияние на метаболизм липидов. Стандартизированный экстракт A. melanocarpa, используемый в качестве добавки против метаболического синдрома, обладает способностью снижать кровяное давление и оказывает положительное влияние на работу сердца. Он улучшает толерантность к глюкозе, ослабляет патологические изменения печени и уменьшает окислительный стресс, присутствующий в условиях метаболического синдрома (Standardized ..., 2018).

Ряд работ посвящен изучению влияния экстрактов аронии на метаболизм холестерина. Исследовано влияние in vivo экстракта аронии на мембраны эритроцитов у пациентов с гиперхолестеринемией. Добавление аронии в рацион пациентов в течение двух месяцев привело к снижению концентрации холестерина на $22 \%$ и уменьшению перекисного окисления липидов на 40 \%, а также к увеличению текучести мембран (In vivo ..., 2012).

\section{Механизм воздействия на процессы, способствующие долголетию}

Несколько работ посвящено изучению воздействие экстракта аронии черноплодной на систему свертывания крови. В исследованиях in vitro показано, что экстракт $A$. melanocarpa модифицирует гемостаз (табл. 4).

Влияния экстракта из плодов A. melanocarpa на связанные со старением процессы

Таблица 3

\begin{tabular}{|c|c|c|}
\hline Модель & Эфрфрект & Источник литературы \\
\hline $\begin{array}{l}\text { Мышь } \\
\text { (Mus musculus) }\end{array}$ & $\begin{array}{l}\text { Подавление адипогенез в адипоцитах 3T3-L1 и модулирование } \\
\text { накопление жира и резистентность к инсулину у мышей с } \\
\text { индуцированным диетой ожирением. Снижает массу тела у } \\
\text { мышей с ожирением, уменьшает уровень триглицеридов в } \\
\text { сыворотке, холестерина и липопротеинов низкой плотности, }\end{array}$ & Chokeberry extract ..., 2018 \\
\hline
\end{tabular}
повышает чувствительность к инсулину

Пациент с метаболическим синдромом

Пациент с метаболическим синдромом Мышь (Mus musculus)

Мышь (Mus musculus) Культура клеток
Изменение активности холинэстеразы крови. Снижение общего холестерина, лПНП и триацилглицерина, снижение уровня перекисного окисления липидов

Снижение уровня маркеров артериального давления, эндотелина в сыворотке, липидов и окислительного стресса Улучшение метаболизма липидов в печени за счет снижения экспрессии PPARY2 и его генов-мишеней aP2 и LPL, индукция экспрессии NRF. Снижение FFA-индуцированных накоплений липидных капель благодаря ингибированию передачи сигналов PPARY2 в гепатоцитах

Улучшение антиоксидантной функции и снижение общего уровня холестерина в плазме у мышей, нокаутированных по аполипопротеину E

Нейропротекторное действие на окислительный стресс, вызванный глутаматом, в клетках НТ22. Снижение гибели клеток НТ22, вызванной глутаматом
Changes in cholinesterase ..., 2018

Aronia melanocarpa extract reduced ..., 2010

Aronia melanocarpa extract ameliorates ..., 2017;

Protection ..., 2019

Aronia melanocarpa (chokeberry) polyphenolrich ..., 2013

Neuroprotective..., 2017 
Сводные данные влияния экстракта из плодов A. melanocarpa на процессы долголетия

\begin{tabular}{|c|c|c|}
\hline Объект & Влияние на процессы долголетия & Источник литературы \\
\hline $\begin{array}{l}\text { Культура эндотелиальных } \\
\text { клеток линии Сасо-2 }\end{array}$ & Предотвращает воспалительный стресс & $\begin{array}{l}\text { Aronia (Aronia melanocarpa) } \\
\text { polyphenols ..., } 2018\end{array}$ \\
\hline Тромбоциты & $\begin{array}{l}\text { Снижает спонтанную и ADP-активированную } \\
\text { адгезию, ингибирует амидолитическую активность } \\
\text { тромбина и плазмина }\end{array}$ & $\begin{array}{l}\text { Extract of aronia melanocarpa } \\
\text { modified } \ldots, 2014\end{array}$ \\
\hline Тромбоциты & $\begin{array}{l}\text { Ингибирует карбонилирование и окисление тиола. } \\
\text { Снижает уровень перекисного окисления липидов, } \\
\text { вызванного пероксинитритом }\end{array}$ & Studies on ..., 2008 \\
\hline Тромбоциты & $\begin{array}{l}\text { Снижает выработку 8-EPI (маркер перекисного } \\
\text { окисления липидов) в контроле и после обработки } \\
\mathrm{H}_{2} \mathrm{O}_{2}\end{array}$ & $\begin{array}{l}\text { Effect of polyphenol-rich extra } \\
2010\end{array}$ \\
\hline $\begin{array}{l}\text { Тромбоциты, обработанные } \\
\mathrm{H}_{2} \mathrm{O}_{2}\end{array}$ & $\begin{array}{l}\text { Снижет активность ферментов супероксиддисму- } \\
\text { таза (SOD), каталаза (CAT) и глутатионпероксидаза } \\
\text { (GPx), увеличивает количество восстановленного } \\
\text { глутатиона }\end{array}$ & Changes of platelet ..., 2011 \\
\hline
\end{tabular}

Были выявлены разнообразные механизмы воздействия экстракта аронии на сердечно-сосудистую систему. Показано влияние биологически активных соединений на сердечно-сосудистую систему при экспериментальной гипертонии: активные вещества уменьшали кровяное давление и индуцировали провоспалительные процессы при гипертонии (Effect of bioactive ..., 2017).

Показано влияние натурального экстракта ягод аронии черноплодной на выработку оксида азота эндотелиальными клетками. Его относительно низкие концентрации (0.1 мкг/мл) значительно индуцировали синтез NO и фосфорилирование eNOS после 10 мин обработки. Повышенная чувствительность еNOS и значительное увеличение синтеза NO обусловлены более длительной стимуляцией с помощью аронии (48 ч) и острой повторной обработкой клеток (10 мин) (Effects of a natural ..., 2016). Экстракт плодов аронии черноплодной проявляет противовоспалительное действие в эндотелиальных клетках аорты человека, ингибируя экспрессию эндотелиальных молекул клеточной адгезии, активацию NF-кB и продукцию активных форм кислорода (Aronia melanocarpa fruit ..., 2012).

Изучено участие богатого полифенолами экстракта $A$. melanocarpa при окислительном стрессе на модели экспериментальной артериальной гипертонии. Все измеренные компоненты артериального давления выявили статистически значимое падение и нормализацию концентрации восстановленного глутатиона (GSH), а также значительное снижение концентрации малонового диальдегида (MDA) (The involvement ..., 2013). Комбинированная терапия статинами и экстрактом из плодов аронии черноплодной способствовала снижению маркеров сердечно-сосудистого риска у пациентов после инфаркта миокарда (Combination ..., 2007).

Некоторые публикации посвящены анализу нейропротекторного действия экстрактов аронии.
Противовоспалительное действие этанольного экстракта аронии черноплодной показано на стимулированные липополисахаридом клетки BV2 и мышей ICR (Anti-neuroinflammatory ..., 2018).

В одной из работ отмечено противовоспалительное действие экстракта аронии в ответ на увеит (воспаление сосудистой оболочки глаза), вызванный эндотоксином у крыс. Противовоспалительный эффект экстракта аронии при заболевании глаз обусловлен прямой блокировкой экспрессии ферментов iNOS и COX-2 и приводит к подавлению продукции NO, PGE2 и TNF- $\alpha$ (Antiinflammatory ..., 2005).

В нескольких работах рассмотрено воздействие экстракта аронии на инсулиновую сигнализацию и его использование в терапии сахарного диабета. Изучено влияние ягод аронии черноплодной на модели диабета первого типа in vivo и in vitro. Показано, что экстракт аронии вызывал уменьшение уровня глюкозы в крови, а также обладал защитным эффектом на $\beta$-клетки поджелудочной железы (The effect of ..., 2018). Экстракты из аронии существенно снижали выработку фибриногена у диабетических крыс по сравнению с контрольной группой крыс с диабетом. Природные полифенолы, выделенные из A. melanocarpa, моделировали специфическую и неспецифическую иммунную защиту, снижали воспалительный статус и способствовали поддержанию уровня инсулина при инсулин-дефицитном диабете (Badescu, 2015).

Экстракт аронии черноплодной снижал прибавку в весе и факторы риска, связанные с резистентностью к инсулину, путем модулирования инсулиновых, адипогенных и провоспалительных сигнальных каскадов эпидидимальной жировой ткани крыс, получавших богатую фруктозой диету (Qin, 2012).

Экстракты из ягод аронии могут обеспечивать защиту от токсического воздействия металлов. Так, в экспериментах на крысах было продемон- 
стрировано, что вещества из ягод аронии предотвращают вызванный кадмием окислительный стресс в печени (Extract from aronia ..., 2018). Экстракт аронии улучшал биосинтез костного коллагена и биомеханические свойства бедренной кости. Потребление продуктов из аронии при воздействии кадмия может улучшить биомеханические свойства кости и защитить ее от переломов (Protective effect ..., 2017).

Гастропротекторное действие A. melanocarpa показано на модели острого геморрагического поражения желудка крыс. Защитное действие экстракта аронии черноплодной и его гидролизата, вводимых в дозе 2 г/кг массы тела, опосредовано регуляцией сигналов HSP-70, NF-кB и MCP-1 (Aronia melanocarpa (Black chokeberry) ..., 2017). Фракция красного пигмента из аронии черноплодной имеет аналогичное значительное защитное действие на слизистую оболочку желудка (Gastroprotective ..., 2004). Обогащенный антоцианинами экстракт из A. melanocarpa вызывал блокаду клеточного цикла в клетках рака толстой кишки, но не влиял на нормальные клетки толстой кишки (Anthocyanin-rich ..., 2003).

Некоторые работы выявили противораковую активность экстрактов аронии черноплодной. Так, была показана индукция апоптоза и снижение экспрессии генов матриксных металлопротеиназ (MMP) в клеточной линии U373 полифенолами A. melanocarpa. Результаты ОТ-ПЦР доказывают подавление экспрессии генов МMP-2, -14, -16 и -17 (Induction ..., 2012).

Экстракт из ягод аронии моделировал образование супероксидных анионных радикалов в тромбоцитах у больных раком молочной железы. Отмечалось статистически значимое увеличение биомаркеров окислительного стресса, таких как $\mathrm{O}^{2-}$, и снижение GSH в тромбоцитах у пациентов с раком молочной железы по сравнению со здоровой группой. Продемонстрирована защитная роль экстракта $A$. melanocarpa у пациентов с раком молочной железы в экспериментах in vitro (Changes of platelet ..., 2011).

Выявлена антиоксидантная активность экстрактов аронии черноплодной, цитотоксическое действие их антоциановой фракции на клетки опухоли шейки матки человека HeLa. Цианидингликозиды ингибировали пролиферацию клеток опухоли шейки матки человека HeLa и увеличивали образование активных форм кислорода после 48 ч обработки. Это позволяет предположить, что они могут быть ответственны за антипролиферативную активность (Antioxidant ..., 2012).

\section{Дополнительные активности}

Для проверки эффективности аронии черноплодной в отношении различных штаммов сезонного и устойчивого к вирусу гриппа В был использован вирусный анализ. Экстракт аронии в низких концентрациях ингибировал почти 70 \% вирусных бляшек вирусов Н1 и Н3, а также устойчивый штамм Н1/K2785. Эти эффекты были приписаны двум составляющим - эллаговой кислоте и мирицетину, которые можно использовать в качестве средств от гриппа (Fruits ..., 2017).

Антибактериальная активность экстрактов из листьев, ягод и стеблей $A$. melanocarpa была изучена для семи концентраций $(19.5,39.1,78.1$, $156.2,312.5,625$ и 1250 мкг/мл) против двух грамположительных (Staphylococcus aureus, Bacillus subtilis) и четырех грамотрицательных (Escherichia coli, Klebsiella pneumonia, Proteus vulgaris, Proteus mirabilis) бактериальных штаммов. Противогрибковую активность определяли в отношении двух видов грибов (Candida albicans, Aspergillus niger) в одинаковом диапазоне концентраций. Согласно полученным результатам, Klebsiella pneumonia оказалась наиболее устойчивой к исследуемому экстракту. Наибольшую антимикробную активность наблюдали при взаимодействии экстракта из стеблей аронии с минимальной концентрацией (19.5 мкг/мл) к Proteus mirabilis (Comparative ..., 2018).

\section{Заключение}

В результате анализа опубликованных данных следует заключить, что Aronia melanocarpa является потенциальным геропротектором, так как соответствует нескольким основным критериям геропротекторов (Developing ..., 2016):

- выявлено увеличение продолжительности жизни у самцов Drosophila melanogaster (медиальной на $18 \%$, а максимальной на $9 \%$ ) под воздействием экстрактов аронии (Јо, 2017);

- наблюдается улучшение биомаркеров старения в виде изменения активности холинэстеразы крови и снижения общего холестерина, ЛПНП и триацилглицерина, также снижение уровня перекисного окисления липидов (Changes in cholinesterase ..., 2018);

- побочные и токсические эффекты аронии черноплодной не обнаружены;

- отмечается эволюционный консерватизм мишени. Обнаружено улучшение метаболизма липидов в печени за счет снижения экспрессии PPAR 2 и его генов-мишеней aP2 и LPL (Aronia melanocarpa extract ..., 2017) и индукции экспрессии NRF (Protection ..., 2019);

- установлено одновременное влияние на несколько ассоциированных со старением причин смерти млекопитающих и человека. Выявлена антимикробная активность экстракта из стеблей аронии на грамотрицательные бактерии (Comparative ..., 2018);

- в экспериментах на крысах было показано увеличение стрессоустойчивости: вещества из ягод аронии предотвращают вызванный кадмием окислительный стресс в печени (Extract from Aronia ..., 2018); 
Таким образом, арония черноплодная соответствует большинству критериев геропротекторов, однако ее влияние на качество жизни еще не изучено и может являться предметом последующих исследований. Необходимы дальнейшие изыскания в области применения и влияния экстрактов аронии в качестве геропротектора как на модельных объектах, так и в клинических испытанияX.

Исследования выполнены в ралках государственного задания по телам "Молекулярно-генетические механизмы старения, продолжительности жизни и cmpecсоустойчивости Drosophila melanogaster" № AAAA-A18-118011120004-5 и «Разработка геропротекторных и радиопротекторных препаратов» № AAAA-A19-119021590022-2.

\section{ЛИТЕРАТУРА}

Влияние препаратов, содержащих фитоэкдистероиды и стероидные гликозиды растений, на продолжительность жизни и стрессоустойчивость Drosophila melanogaster / М. В. Шапошников, Л. А. Шилова, Е. Н. Плюснина, С. О. Володина, В. В. Володин, А. А. Москалев // Экологическая генетика. - 2014. - Т. 12, № 4. - C. 3-14. - doi: 10.17816/ecogen1243-14

Anthocyanin-rich extract from Aronia meloncarpa E induces a cell cycle block in colon cancer but not normal colonic cells / M. Malik, C. Zhao, N. Schoene, M. Guisti, M. Moyer, B. Magnuson // Nutr Cancer. - 2003. - N 46 (2). - P. 186-196.

Anti-neuroinflammatory effects of ethanolic extract of black chokeberry (Aronia melanocapa L.) in lipopolysaccharide-stimulated BV2 cells and ICR mice / K. P. Lee, N. H. Choi, H. S. Kim, S. Ahn, I. S. Park, D. W. Lee // Nutr Res Pract. - 2018. - N 12 (1). - P. 13-19. doi: $10.4162 /$ nrp.2018.12.1.13

Anti-inflammatory effects of aronia extract on rat endotoxin-induced uveitis / K. Ohgami, I. Ilieva, K. Shiratori, Y. Koyama, X. H. Jin, K. Yoshida, S. Kase, N. Kitaichi, Y. Suzuki, T. Tanaka, S. Ohno // Invest Ophthalmol Vis Sci. - 2005. - N 46 (1). -P. 275-281. - doi: 10.1167/iovs.04-0715

Antioxidant activities of chokeberry extracts and the cytotoxic action of their anthocyanin fraction on HeLa human cervical tumor cells / D. Rugina, Z. Sconta, L. Leopold, A. Pintea, A. Bunea, C. Socaciu // J Med Food. 2012. - N 15 (8). - P. 700-706. - doi: 10.1089/ jmf.2011.0246

Aronia (Aronia melanocarpa) polyphenols modulate the microbial community in a simulator of the human intestinal microbial ecosystem (SHIME) and decrease secretion of proinflammatory markers in a Caco-2/ endothelial cell coculture model / T. Wu, C. Grootaert, J. Pitart, N. K. Vidovic, S. Kamiloglu, S. Possemiers, M. Glibetic, G. Smagghe, K. Raes , T. Van de Wiele, J. Van Camp // Mol Nutr Food Res. - 2018. - N 62 (22). - P. 1800607. - doi: 10.1002/mnfr.201800607

Aronia melanocarpa (Black Chokeberry) reduces ethanol-induced gastric damage via eegulation of HSP-70, NF- $\mathrm{kB}$, and MCP-1 signaling / A. Paulrayer, A. Adithan, J. H. Lee, K. H. Moon, D. G. Kim, S. Y. Im, C. W. Kang, N. S. Kim, J. H. Kim // Int J Mol Sci. - 2017. N 18 (6). - pii: E1195. - doi: 10.3390/ijms18061195

Aronia melanocarpa (chokeberry) polyphenol-rich extract improves antioxidant function and reduces total plasma cholesterol in apolipoprotein E knockout mice / B. Kim, C. S. Ku, T. X. Pham, Y. Park, D. A. Martin, L. Xie, R. Taheri, J. Lee, B. W. Bolling // Nutr Res. -
2013. - N 33 (5). - P. 406-413. - doi: 10.1016/ j.nutres.2013.03.001

Aronia melanocarpa extract ameliorates hepatic lipid metabolism through PPAR $\gamma 2$ downregulation / C. H. Park, J. H. Kim, E. B. Lee, W. Hur, O. J. Kwon, H. J. Park, S. K. Yoon // PLoS One. - 2017. - 12(1):e0169685. doi: 10.1371/journal.pone.0169685

Aronia melanocarpa extract reduces blood pressure, serum endothelin, lipid, and oxidative stress marker levels in patients with metabolic syndrome / M. Broncel, M. Kozirog, P. Duchnowicz, M. Koter-Michalak, J. Sikora, J. Chojnowska-Jezierska // Med Sci Monit. 2010. - N 16 (1). - P. 28-34.

Aronia melanocarpa fruit extract exhibits anti-inflammatory activity in human aortic endothelial cells / D. Zapolska-Downar, D. Bryk, M. Malecki, K. Hajdukiewicz, D. Sitkiewicz // Eur J Nutr. - 2012. - N 51 (5). - P. 563572. - doi: 10.1007/s00394-011-0240-1

Badescu, M. Effects of Sambucus nigra and Aronia melanocarpa extracts on immune system disorders within diabetes mellitus / M. Badescu, O. Badulescu, L. Badescu, M. Ciocoiu // Pharm Biol. - 2015. - N 53 (4). - P. 533539. - doi: 10.3109/13880209.2014.931441. Epub 2014 Oct 20

Black chokeberry (Aronia melanocarpa): biological activity and prospects in medicine / I. V. Safronova, I. A. Goldina, K. V. Gaidul, V. A. Kozlov // J Innovation and food security. - 2014. - N (3). - P. 32-43. - doi: 10.1111/1541-4337.12221

Borowska, S. Chokeberries (Aronia melanocarpa) and their products as a possible means for the prevention and treatment of noncommunicable diseases and unfavorable health effects due to exposure to xenobiotics: Aronia melanocarpain health protection / S. Borowska, M. Brzoska // Comprehensive Reviews in Food Science and Food Safety. - 2016. - N 15 (6). - doi: 10.1111/1541-4337. 12221

Changes in Cholinesterase Activity in Blood of Adolescent with Metabolic Syndrome after Supplementation with Extract from Aronia melanocarpa / P. Duchnowicz, A. Ziobro, E. Rapacka, M. Koter-Michalak, B. Bukowska // Biomed Res Int. - 2018. - 2018:5670145. - doi: $10.1155 / 2018 / 5670145$. eCollection 2018

Changes of platelet antioxidative enzymes during oxidative stress: the protective effect of polyphenol-rich extract from berries of Aronia melanocarpa and grape seeds / M. Kedzierska, B. Olas, B. Wachowicz, A. Stochmal, W. Oleszek, J. Erler // Platelets. - 2011. - N 22 (5). - P. 385-389. - doi: 10.3109/09537104.2010. 545151. Epub 2011 Feb 7

Chokeberry extract and its active polyphenols suppress adipogenesis in 3T3-L1 adipocytes and modulates fat accumulation and insulin resistance in diet-Induced obese mice / N. H. Kim, J. Jegal, Y. N. Kim, J. D. Heo, J. R. Rho, M. H. Yang, E. J. Jeong // Nutrients. - 2018. N 10 (11). - pii: E1734. - doi: 10.3390/nu10111734

Combination therapy of statin with flavonoids rich extract from chokeberry fruits enhanced reduction in cardiovascular risk markers in patients after myocardial infraction (MI) / M. Naruszewicz, I. Laniewska, B. Millo, M. Dluzniewski / / Atherosclerosis. - 2007. - N 194 (2). P. 179-184. - doi: 10.1016/j.atherosclerosis.2006.12. 032

Comparative in vitro studies of the biological potential and chemical composition of stems, leaves and berries Aronia melanocarpa's extracts obtained by subcritical water extraction / A. Cvetanovic, G. Zengin, Z. Zekovic, J. Svarc-Gajic, S. Razic, A. Damjanovic, P. Maskovic, M. Mitic // Food Chem Toxicol. - 2018. N 121. - P. 458466. - doi: 10.1016/j.fct.2018.09.045. Epub 2018 Sep 21 
Developing criteria for evaluation of geroprotectors as a key stage toward translation to the clinic / A. Moskalev, M. Shaposhnikov, A. Fedintsev, A. Zhavoronkov, E. Chernyagina, V. Tsvetkov, V. Krut'ko, B. Kennedy // J Aging cell. - 2016. - N 15 (3). - P. 407-415. - doi: 10.1111 /acel.12463

Effects of a natural extract of Aronia melanocarpa berry on endothelial cell nitric oxide production / C. E. Varela, E. Fromentin, M. Roller, F. Villarreal, I. RamirezSanchez // J Food Biochem. - 2016. - N 40 (4). - P. 404410. - doi: 10.1111/jfbc.12226.

Effects of Abies sibirica terpenes on cancer- and agingassociated pathways in human cells / A. Kudryavtseva, G. Krasnov, A. Lipatova, B. Aleksee, F. Maganov, M. Shaposhnikov, M. Fedorov, A. Snezhkina, A. Moskalev // Oncotarget. - 2016. - N 7 (50). - P. 83744-83754. doi: 10.18632/oncotarget.13467

Effect of bioactive compound of Aronia melanocarpa on cardiovascular system in experimental hypertension / M. Cebova, J. Klimentova, P. Janega, O. Pechanova // Oxid Med Cell Longev. - 2017. -2017:8156594. - doi: $10.1155 / 2017 / 8156594$. Epub 2017 Nov 30

Effects of polyphenol-rich extract from berries of Aronia melanocarpa on the markers of oxidative stress and blood platelet activation / B. Olas, M. Kedzierska, B. Wachowicz, A. Stochmal, W. Oleszek // Platelets. 2010. - N 21 (4). - P. 274-281. - doi: 10.3109/ 09537101003612821

Eremeeva, N. B. Antioxidant activity of chokeberry extracts obtained in supercritical condition / N. B. Eremeeva, N. V. Platonov, I. A. Makarova // Food Processing. - 2016. - Vol. 42, N 3. - P.12-18.

Extract from Aronia melanocarpa L. Berries Prevents Cadmium-Induced oxidative stress in the liver: a study in a rat model of low-level and moderate lifetime human exposure to this toxic metal / M. Mezynska, M. Brzoska, J. Rogalska, B. Pilat-Marcinkiewicz // Nutrients. 2018. - N 11 (1). - pii: E21. - doi: 10.3390/nu11010021

Extract of Aronia melanocarpa-modified hemostasis: in vitro studies / J. Sikora, M. Markowicz-Piasecka, M. Broncel, E. Mikiciuk-Olasik // Eur J Nutr. - 2014. N 53 (7). - P. 1493-502. - doi: 10.1007/s00394-0140653-8

Fontana, L. Promoting health and longevity through diet: from model organisms to humans / L. Fontana, L. Partridge // Cell. - 2015. - N 161 (1). - P. 106118. - doi: 10.1016/j.cell.2015.02.020

Fruits of Black Chokeberry Aronia melanocarpa in the prevention of chronic diseases / T. Jurikova, J. Mlcek, S. Skrovankova, D. Sumczynski, J. Sochor, I. Hlavacova, L. Snopek, J. Orsavova // Molecules. - 2017. - N 22 (6). - pii: E944. - doi: 10.3390/molecules22060944

Fucoxanthin increases lifespan of Drosophila melanogaster and Caenorhabditis elegans / E. Lashmanova, E. Proshkina, S. Zhikrivetskaya, O. Shevchenko, E. Marusich, S. Leonov, A. Melerzanov, A. Zhavoronkov, A. Moskalev // Pharmacol Res. - 2015. - N 100. P. 228-241. - doi: 10.1016/j.phrs.2015.08.009

Gastroprotective effect of red pigments in black chokeberry fruit (Aronia melanocarpa Elliot) on acute gastric hemorrhagic lesions in rats / M. Matsumoto, H. Hara, H. Chiji, T. Kasai // J Agric Food Chem. - 2004. - N 52 (8). - P. 2226-2229. - doi: 10.1021/jf034818q

Geroprotective and radioprotective activity of quercetin, (-)-epicatechin, and ibuprofen in Drosophila melanogaster / E. Proshkina, E. Lashmanova, E. Dobrovolskaya, N. Zemskaya, A. Kudryavtseva, M. Shaposhnikov, A. Moskalev // Front Pharmacol. - 2016. - N 7:505. - doi: 10.3389/fphar.2016.00505

Hudec, J. Content of phenolic compounds and free polyamines in black chokeberry (Aronia melanocarpa) after application of polyamine biosynthesis regulators / J. Hudec / Journal of agricultural and food chemistry. 2006. - N 54 (10). - P. 3625-3628. - doi: 10.1021/ jf060299q

Induction of apoptosis and reduction of MMP gene expression in the U373 cell line by polyphenolics in Aronia melanocarpa and by curcumin / N. A. Abdullah, B. Sallis, R. Nuttall, F. R. Schubert, M. Ahsan, D. Davies, S. Purewal, A. Cooper, H. K. Rooprai // Oncol Rep. 2012. - N 28(4). - P. 1435-1442. - doi: 10.3892/ or.2012.1941. Epub 2012 Jul 27

In vivo influence of extract from Aronia melanocarpa on the erythrocyte membranes in patients with hypercholesterolemia / P. Duchnowicz, A. Nowicka, M. KoterMichalak, M. Broncel // Med Sci Monit. - 2012. - N 18 (9). - CR569-74.

Jo, A. R. Effects of Aronia extract on lifespan and age-related oxidative stress in Drosophila melanogaster / A. R. Jo, J. Y. Imm // Food Sci Biotechnol. - 2017. N 26 (5). - P. 1399-1406. - doi: 10.1007/s10068-0170180-5. eCollection 2017

Kokotkiewicz, A. Aronia plants: a review of traditional use, biological activities, and perspectives for modern medicine / A. Kokotkiewicz, Z. Jaremicz, M. Luczkiewicz // J Med Food. - 2010. - N 13 (2). - P. 255-269. doi: $10.1089 /$ jmf. 2009.0062

Neuroprotective effect of Aronia melanocarpa extract against glutamate-induced oxidative stress in HT22 cells / H. Y. Lee, J. B. Weon, G. Ryu, W. S. Yang, N. Y. Kim, M. K. Kim, C. J. Ma // BMC complementary and alternative medicine. - 2017. - Vol. 17 (1). - P. 207. - doi: 10.1186/s12906-017-1716-1

Protection from DNA damage by use of an aronia food supplement-results from a pilot human intervention study / T. Bakuradze, D. Becker, J. Reischmann, P. Meiser, J. Galan, E. Richling // Current Pharmacology Reports. - 2019. - N 5 (3). - P. 188-195. -doi:10.1007/ s40495-019-00178-5

Protective effect of chokeberry (Aronia melanocar$p a$ L.) extract against cadmium impact on the biomechanical properties of the femur: a study in a rat model of low and moderate lifetime women exposure to this heavy metal / M. Brzoska, A. Roszczenko, J. Rogalska, M. Galazyn-Sidorczuk, M. Mezynska // Nutrients. - 2017. N 9 (6). - pii: E543. - doi: 10.3390/nu9060543

Qin, B. An extract of chokeberry attenuates weight gain and modulates insulin, adipogenic and inflammatory signalling pathways in epididymal adipose tissue of rats fed a fructose-rich diet / B. Qin, R.A. Anderson // Br J Nutr. - 2012. - N 108 (4). - P. 581-587. - doi: 10.1017/ S000711451100599X

Razungles, A. Determination of carotenoids in fruits of Rosa sp. (Rosacanina and Rosarugosa) and of chokeberry (Aronia melanocarpa) / A. Razungles, J. Oszmianski, J. Sapis // J. Food Sci. - 1989. - Vol. 54. - P. 774775. - doi: 10.1111/j.1365-2621.1989.tb04709.x

Rugina, D. Chokeberry Anthocyanin Extract as Pancreatic $\beta$-Cell Protectors in Two Models of Induced Oxidative Stress / D. Rugina // Oxidative medicine and cellular longevity. - 2015. - p. 429-475. - doi: 10.1155/ $2015 / 429075$

Standardized Aronia melanocarpa extract as novel supplement against metabolic syndrome: a rat model / V. Jakovljevic, P. Milic, J. Bradic, J. Jeremic, V. Zivkovic, I. Srejovic, T. Turnic, I. Milosavljevic, N. Jeremic, S. Bolevich, B. Labudovic, M. Mitrovic, V. Vucic // Int J Mol Sci. - 2018. - N 20 (1). - pii: E6. - doi: 10.3390/ ijms 20010006

Studies on antioxidant properties of polyphenol-rich extract from berries of Aronia melanocarpa in blood platelets / B. Olas, B. Wachowicz, P. Nowak, M. Kedzier- 
ska, A. Tomczak, A. Stochmal, W. Oleszek, A. Jeziorski, J. Piekarski // J Physiol Pharmacol. - 2008. - N 59 (4). - P. 823-835.

The effect of aronia berry on type 1 diabetes in vivo and in vitro / Y. D. Jeon, S. H. Kang, K. H. Moon, J. H. Lee, D. G. Kim, W. Kim, J. S. Kim, B. Y. Ahn, J. S. Jin // J Med Food. - 2018. - N 21 (3). - P. 244-253. - doi: 10.1089/jmf.2017.3939. Epub 2018 Feb 22

The effects of pectins on life span and stress resistance in Drosophila melanogaster / M. Shaposhnikov, D. Latkin, E. Plyusnina, L. Shilova, A. Danilov, S. Popov, A. Zhavoronkov, Y. Ovodov, A. Moskalev // Biogerontology. 2014. - N 15 (2). - P. 113-127. - doi: 10.1007/s10522013-9484-x

The evaluation of geroprotective effects of selected flavonoids in Drosophila melanogaster and Caenorhabditis elegans / E. Lashmanova, N. Zemskaya, E. Proshkina, A. Kudryavtseva, M. Volosnikova, E. Marusich, S. Leonov, A. Zhavoronkov, A. Moskalev // Front Pharmacol. 2017. N 8. - P. 884. - doi: 10.3389/fphar.2017.00884

The involvement of a polyphenol-rich extract of black chokeberry in oxidative stress on experimental arterial hypertension / M. Ciocoiu, L. Badescu, A. Miron, M. Badescu / / Evid Based Complement Alternat Med. - 2013. doi: 10.1155/2013/912769. Epub 2013 Feb 27
Thi, N. D. Bioactive compound contents and antioxidant activity in Aronia (Aronia melanocarpa) leaves collected at different growth stages / N. D. Thi, E. S. Hwang // Prev Nutr Food Sci. - 2014. - N 19 (3). P. 204-212. - doi:10.3746/pnf.2014.19.3.204

Thi, N. D. Effects of drying methods on contents of bioactive compounds and antioxidant activities of black chokeberries (Aronia melanocarpa) / N. D. Thi, E. S. Hwang // Food Sci Biotechnol. - 2016. - N 25 (1). P. 5561. - doi: 10.1007/s10068-016-0008-8

Transcriptome analysis reveals mechanisms of geroprotective effects of fucoxanthin in Drosophila / A. Moskalev, M. Shaposhnikov, N. Zemskaya, A. Belyi, E. Dobrovolskaya, A. Patova, Z. Guvatova, E. Lukyanova, A. Snezhkina, A. Kudryavtseva // BMC Genomics. 2018. - N 19 (Suppl 3):77. - doi: 10.1186/s12864-0184471-x

Underutilized chokeberry (Aronia melanocarpa, Aronia arbutifolia, Aronia prunifolia) accessions are rich sources of anthocyanins, flavonoids, hydroxycinnamic acids, and proanthocyanidins / R. Taheri, B. A. Connolly, M. H. Brand, B. W. Bolling // J Agric Food Chem. 2013. - N 61 (36). - P. 8581-8588. - doi: 10.1021/ jf $402449 q$

\title{
BLACK CHOKEBERRY ARONIA MELANOCARPA IS THE PROMISING SOURCE OF SUBSTANCES KNOWN AS POTENTIAL GEROPROTECTORS
}

\author{
E.Y. Platonova', S.N. Plusnin², M.V. Shaposhnikov' ${ }^{1}$, A.A. Moskalev ${ }^{1,2}$ \\ ${ }^{1}$ Institute of Biology of Komi Scientific Centre of the Ural Branch of the Russian Academy of Sciences, Syktyvkar \\ ${ }^{2}$ Syktyvkar State University Pitirim Sorokin, Syktyvkar
}

\begin{abstract}
Summary. Aronia melanocarpa was reported as a plant which extracts impact on model organisms' aging and intracellular processes. In previously published studies an increase in the median lifespan (by $18 \%$ ) of Drosophila melanogaster was found as well as maximal lifespan prolongation by $9 \%$. There was an improvement in lipid metabolism in the liver and a decrease in the expression of PPAR?2 and its $a P 2$ and $L P L$ target genes. Slow growth of malignant cell lines (HeLa, A-549, LS-174T) and normal lung fibroblasts (MRC-5) under the influence of chokeberry extracts from the stems, leaves and berries was described in the review. Antimicrobial activity was shown on Gram-negative bacterial strain Proteus mirabilis treated with $19.53 \mu \mathrm{g} / \mathrm{ml}$ aronia stem extract. The injected extract of chokeberry and its hydrolyzate, in the amount of $2 \mathrm{~g} / \mathrm{kg}$ of body weight exhibits a protective effect when the mucous membrane of the rat's stomach is damaged by $30 \%$ of ethanol comparing with the control group in the experiment. The effect of in vivo treatment by aronia extract on erythrocyte membranes in patients with hypercholesterolemia was studied. The two-month addition of chokeberry in the diet of patients led to a decrease in cholesterol levels by $22 \%$ and a reduction in lipid peroxidation by $40 \%$ and to a membrane fluidity improvement. In addition, the effect of chokeberry Aronia berries on type 1 diabetes in vivo and in vitro was studied. Aronia fruit extract causes an effect on the level of glucose in the blood, and also has a protective effect on ?-cells of the pancreas. To conclude, the assumption that aronia may be a source of substances possessing geroprotective properties is confirmed.
\end{abstract}

Key words: Aronia melanocarpa, extract, geroprotector, lifespan, polyphenolic compounds, anthocyanins 